\title{
Densified HKUST-1 Monoliths as a Route to High Volumetric and Gravimetric Hydrogen Storage Capacity
}

David G. Madden, ${ }^{\mathrm{a}} \uparrow *$ Daniel O’Nolan, ${ }^{\mathrm{b}} \uparrow$ Nakul Rampal, ${ }^{\mathrm{a}} \uparrow$ Robin Babu, ${ }^{\mathrm{a}}$ Ceren Çamur, ${ }^{\mathrm{a}}$ Ali N. Al Shakhs, ${ }^{\mathrm{a}}$ Shi-Yuan Zhang, ${ }^{\text {a }}$ Graham A. Rance,,${ }^{c, d}$ Javier Perez, ${ }^{\mathrm{e}}$ Nicola Pietro Maria Casati, ${ }^{\mathrm{f}}$ Carlos Cuadrado-Collados, ${ }^{\mathrm{g}}$ Denis O'Sullivan, ${ }^{\mathrm{h}}$ Nicholas P. Rice, ${ }^{\mathrm{h}}$ Thomas Gennett, ${ }^{\mathrm{i}}$ Philip Parilla, ${ }^{\mathrm{i}}$ Sarah Shulda, ${ }^{\mathrm{i}}$ Katherine E. Hurst, ${ }^{\mathrm{i}}$ Vitalie Stavila, ${ }^{j}$ Mark D. Allendorf, ${ }^{j}$ Joaquin Silvestre-Albero, ${ }^{\mathrm{g}}$ Alexander C. Forse, ${ }^{\mathrm{k}}$ Neil R. Champness, ${ }^{1}$ Karena W. Chapman ${ }^{\mathrm{b} *}$ and David Fairen-Jimenez ${ }^{\mathrm{a} *}$

${ }^{a}$ The Adsorption \& Advanced Materials Laboratory $\left(A^{2} M L\right)$, Department of Chemical Engineering \& Biotechnology, University of Cambridge, Philippa Fawcett Drive, Cambridge CB3 OAS, UK

${ }^{b}$ Department of Chemistry, Stony Brook University, Stony Brook, New York 11790-3400, United States

${ }^{c}$ Nanoscale and Microscale Research Centre (nmRC), University of Nottingham, University Park, Nottingham, $N G 72 R D$.

${ }^{d}$ School of Chemistry, University of Nottingham, University Park, Nottingham, NG7 2RD.

${ }^{e}$ Synchrotron SOLEIL, Gif sur Yvette Cedex, France

${ }^{f} 10$ Laboratory for Synchrotron Radiation -Condensed Matter, Paul Scherrer Institute, 5232 Villigen-PSI, 11 Switzerland.

${ }^{g}$ Laboratorio de Materiales Avanzados (LMA), Departamento de Química Inorgánica-IUMA, Universidad de Alicante, 03690 San Vicente del Raspeig, Spain

hImmaterial Ltd., 25 Cambridge Science Park, Milton Road, Cambridge CB4 OFW, UK

${ }^{i}$ Materials and Chemical Science and Technology Directorate, National Renewable Energy Laboratory, Golden, Colorado 80401, United States

${ }^{j}$ Chemistry, Combustion, and Materials Science Center, Sandia National Laboratories, Livermore, California 94551, United States

${ }^{k}$ Yusuf Hamied Department of Chemistry, University of Cambridge, Cambridge CB2 1EW, UK

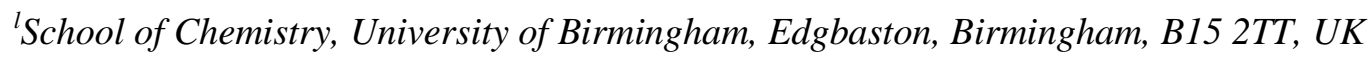

*E-mail:_dm850@cam.ac.uk,karena.chapman@stonybrook.edu,df334@cam.ac.uk

†These authors contributed equally

We are currently witnessing the dawn of the hydrogen $\left(\mathrm{H}_{2}\right)$ economy, where $\mathrm{H}_{2}$ will become a primary fuel for heating, transportation, and long-distance and long-term energy storage. Among the diverse possibilities, $\mathrm{H}_{2}$ can be stored as a pressurized gas, cryogenic liquid, or solid fuel via adsorption onto porous materials. Metal-organic frameworks (MOFs) have emerged as the adsorbent materials with the theoretical highest $\mathrm{H}_{2}$ storage densities on both a volumetric and gravimetric basis. However, a critical bottleneck for the use of $\mathrm{H}_{2}$ as a transportation fuel has been the lack of densification methods capable of shaping MOFs into practical formulations whilst maintaining their adsorptive performance. Here, we report a high-throughput screening and deep analysis of a database of MOFs to find optimal materials, followed by the synthesis, characterisation, and performance evaluation of an optimal monolithic MOF (monoMOF) for $\mathrm{H}_{2}$ storage. After densification, this mono MOF stores $46 \mathrm{~g} \mathrm{~L}^{-1} \mathrm{H}_{2}$ at $50 \mathrm{bar}, 77 \mathrm{~K}$, and delivers 41 and 
$42 \mathrm{~g} \mathrm{~L}^{-1} \mathrm{H}_{2}$ at operating pressures of 25 and $50 \mathrm{bar}$, respectively, when deployed in a combined temperature-pressure $(25-50 \mathrm{bar} / 77 \mathrm{~K} \rightarrow 5 \mathrm{bar} / 160 \mathrm{~K})$ swing gas delivery system. This performance represents up to an $80 \%$ reduction in the operating pressure requirements for delivering $\mathrm{H}_{2}$ gas when compared with benchmark materials, and an $83 \%$ reduction compared to compressed $\mathrm{H}_{2}$ gas. Our findings represent a substantial step forward in the application of high-density materials for volumetric $\mathrm{H}_{2}$ storage applications.

We are currently living in a time of great change as global transport transitions away from fossil fuels. As an alternative, $\mathrm{H}_{2}$ gas has long held great promise as a sustainable energy vector and an automotive transportation fuel as part of the $\mathrm{H}_{2}$ economy $(1-3) . \mathrm{H}_{2}$ gas is a clean, potentially green, and non-toxic renewable fuel that contains much greater chemical energy per mass (142 $\mathrm{MJ} \mathrm{kg}^{-1}$ ) when compared to hydrocarbon fuels. The combustion of $\mathrm{H}_{2}$ releases only water vapour as a by-product, allowing $\mathrm{H}_{2}$ fuel cell vehicles (FCV) to potentially provide zero-emission transportation. While containing $c a .3$ times more energy per unit mass than gasoline, its onboard storage presents significant challenges. $\mathrm{H}_{2}$ is a very light gas and displays weak $\mathrm{H}_{2} \cdots \mathrm{H}_{2}$ intermolecular forces and thus requires cryogenic cooling and/or compression for storage at quantities $(>5.6 \mathrm{~kg}$ ) deemed sufficient for driving ranges (ca. 300 miles) comparable to traditional fuels (4).

The US Department of Energy (DOE) set ambitious targets for FCV onboard $\mathrm{H}_{2}$ storage, requiring an initial system (including tank and materials) delivery capacity of $30 \mathrm{~g} \mathrm{~L}^{-1}$ (4.5 wt. \%) and an ultimate target of $50 \mathrm{~g} \mathrm{~L}^{-1}\left(6.5 \mathrm{wt}\right.$ \%). FCVs utilising compressed $\mathrm{H}_{2}$ gas (CHG) and cryocompression methods have already been produced by major automobile manufacturers (BMW, Toyota and Honda). However, these vehicles still require high gas operating pressures ( $>350$ bar) and costly carbon fiber-reinforced storage tanks. Adsorbed gas storage (AGS) is considered a viable alternative to cryogenic or compressive storage, utilising nanoporous materials to boost the hydrogen density in a tank at reduced operating pressures ( $c a .100$ bar). While traditional nanoporous materials such as activated carbons have been widely studied for $\mathrm{H}_{2}$ storage, these materials lack the versatility and structural tunability to be considered viable options for AGS technologies (5-7).

As an alternative, MOFs are a class of nanoporous materials with great potential for gas storage and separation applications. The tunability of this class of materials has given way to the synthesis of over 100,000 reported structures with a large array of interesting properties in terms of chemical and structural diversity $(8,9)$. This versatility of MOFs has seen them widely studied for AGS applications, including $\mathrm{H}_{2}$ and $\mathrm{CH}_{4}$. Several high-surface-area MOFs display benchmark performance with impressive gravimetric and volumetric $\mathrm{H}_{2}$ storage densities, both on the materials and systembased levels (4). Despite these advances, two major issues need to be addressed before MOFs can be deployed in FCVs. Firstly, MOFs generally display Type I isotherms for adsorption of $\mathrm{H}_{2}$ under 
cryogenic conditions (Fig. 1a), with very high loadings at low pressures, followed by a saturation of the $\mathrm{H}_{2}$ uptake at higher pressures. This limits the overall working capacity of the adsorbent materials. To address this issue, the DOE Hydrogen Storage Engineering Center of Excellence (HSECoE) has proposed designing tanks for cryo-adsorption storage that operate with $\mathrm{H}_{2}$ loading occurring at $77 \mathrm{~K}$ and 100 bar and discharge occurring at $160 \mathrm{~K}$ and 5 bar, ensuring the amount of deliverable $\mathrm{H}_{2}$ in nanoporous MOFs is maximised (Fig. 1b) (10).
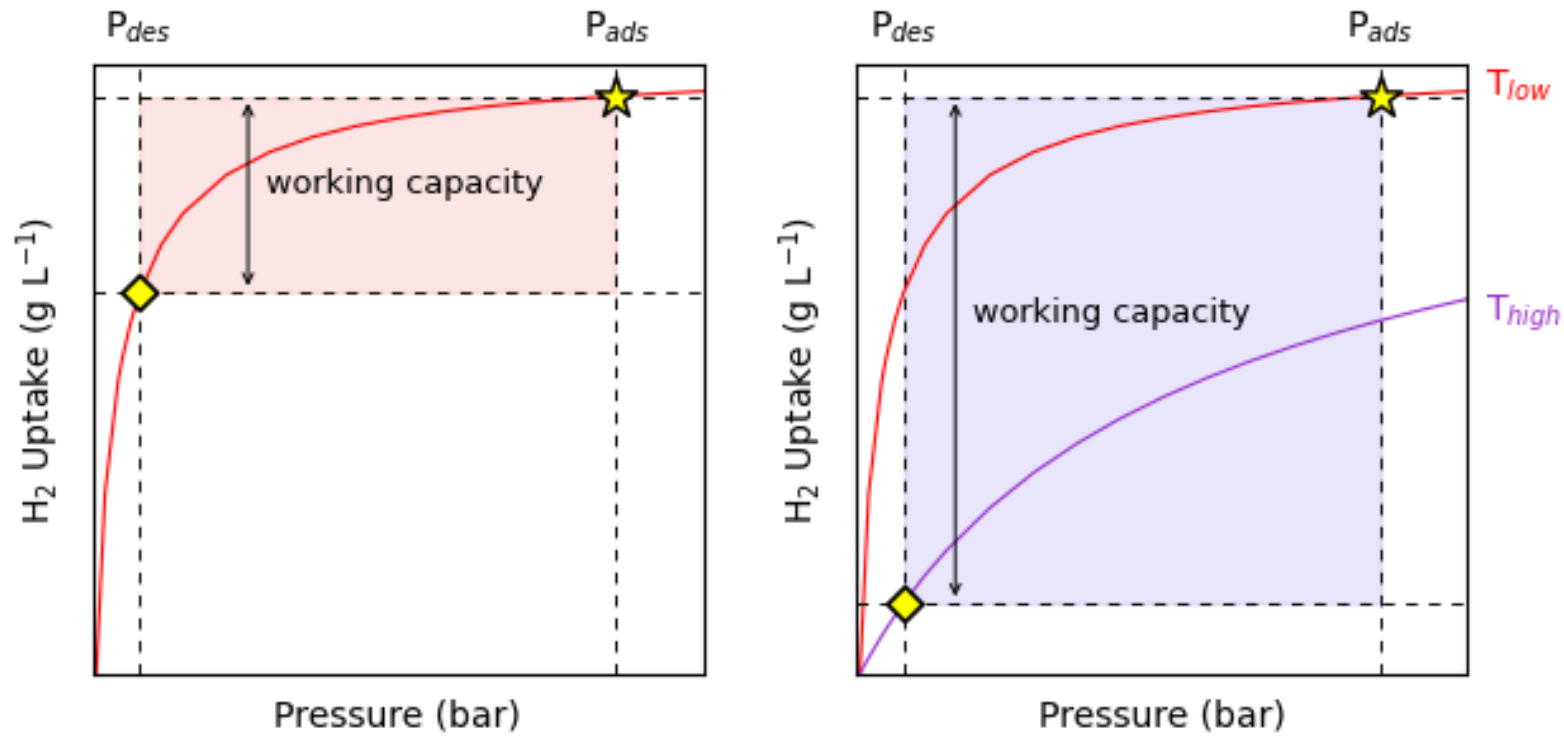

Fig. 1. Idealised $\mathrm{H}_{2}$ Adsorption Isotherms for FCV Storage Systems. Illustration of usable volumetric capacity for $\mathbf{a}$. pressure swing and $\mathbf{b}$. temperature-pressure swing storage systems. Total volumetric adsorption isotherms are shown as purple and red curves, corresponding to high and low temperatures, respectively. The "charged" state of the tank is represented by a gold star and the "discharged" state is represented by gold diamonds. Double-sided arrows represent volumetric usable capacities achieved for each system with $P_{\text {ads }}=$ 100 bar and $P_{\text {des }}=5$ bar.

The second, and arguably more important, issue hampering the deployment of MOFs for gas storage applications regards the shaping and densification of MOF materials. While many MOFs display exceptional gravimetric $\mathrm{H}_{2}$ adsorption capacity, their performance does not readily translate to volumetric performance due to issues relating to MOF densification. MOFs are traditionally synthesised as powders with very low packing density that are formulated into shaped bodies via mechanical processes (11-13). These processes often yield low-density final products or materials with reduced performance as a result of the low pressures used in the processing or structural collapse when the pressures are high $(12,14)$. Despite its importance, this is an area of research that has received relatively low attention, with many researchers choosing to report volumetric values based upon theoretical crystal densities as opposed to experimental bulk densities (15). While theoretical crystal densities play an important role in identifying candidate materials for $\mathrm{H}_{2}$ storage, the final packing densities of shaped materials can often be only a fraction of the theoretical crystal densities. Indeed, many MOFs suffer significant losses in porosity and overall adsorption performance upon 
densification due to pore collapse $(12,16,17)$. As an alternative to the densification of bulk powders, control of particle size, morphology, and monodispersity before densification has recently shown potential for improving the packing densities for MOFs (18).

In this work, we have used first a high-throughput computational screening and principal component analysis (PCA) to evaluate the landscape of the properties required to optimise hydrogen uptake in MOFs and to find an optimal structure, HKUST-1. Then, we used our recent developments in advanced sol-gel synthesis, engineering and densification of MOFs to produce a pure monolithic HKUST-1 (monoHKUST-1) structure of up to about $1 \mathrm{~cm}^{3}$ in size without using high pressures or additional binders $(17,19-21)$. We subsequently examined the unique nature of the local structures of the high-density monoHKUST-1 material using advanced characterisation techniques such as synchrotron X-ray total scattering, mapping pair distribution function (PDF) studies, Raman microscopy and solid-state nuclear magnetic resonance (NMR) spectroscopy studies. Finally, we examined the exceptional adsorption performance of monoHKUST-1 as the top-performing densified MOF for volumetric $\mathrm{H}_{2}$ storage. The performance of monoHKUST-1 suggests that advanced monolithic MOFs could pave the way for a new generation of high performance, high-density adsorbents for both on-board vehicular AGS and stationary applications, dramatically reducing the pressure requirements for onboard $\mathrm{H}_{2}$ storage whilst improving both vehicle safety and driving distances in support of the $\mathrm{H}_{2}$ economy.

\section{High-Throughput Computational Screening of MOFs}

The exceptional tunability of MOFs has led to the experimental synthesis of thousands of MOFs, and the prediction of millions $(8,22)$. To evaluate the landscape of MOFs in hydrogen storage in this vast chemical space, we ran high-throughput screening (HTS) studies by performing grand canonical Monte Carlo (GCMC) simulations on a database of 2,932 experimentally synthesized MOFs at four pressures: 5, 25, 50, and 100 bar; and five temperatures: 77, 160, 198, 233, and $298 \mathrm{~K}$. We went one step further by performing a principal component analysis (PCA) on the vast amount of data generated in the HTS studies. We also highlighted 10 benchmark MOF materials for hydrogen storage in our screening - HKUST-1, MOF-5, NU-100/PCN-100, NU-1501-Al, NU-1500-Al, Ni(dobdc), MIL-101, IRMOF-10, UMCM-9, and IRMOF-20. Although some previous HTS studies have been reported in the literature none have explored the range of conditions considered here (23-25, Supplementary File $1)$.

Figure 2a shows the general landscape of the gravimetric and volumetric surface areas of the MOFs studied here. Benchmark MOF materials such as MOF-5, IRMOF-20 and NU-1500-Al displayed both exceptional gravimetric and volumetric surface areas. While materials such as NU1501-Al and NU-100 displayed high gravimetric surface areas, the denser structure of HKUST-1 
gave way to a higher volumetric surface area. On top of that, for hydrogen tank storage, an ideal MOF structure should not only have high hydrogen storage capacity but, more importantly, should possess a high deliverable capacity (15). To further probe the gas storage/adsorption performance, we determined the theoretical $\mathrm{H}_{2}$ deliverable capacities of the studied MOFs under five different combined temperature-pressure swing gas delivery systems, ranging from purely cryogenic $(25,50$ $\& 100 \mathrm{bar} / 77 \mathrm{~K} \rightarrow 5 \mathrm{bar} / 160 \mathrm{~K})$ to near-ambient $\mathrm{H}_{2}$ delivery $(100 \mathrm{bar} / 198 \mathrm{~K} \& 100 \mathrm{bar} / 233 \mathrm{~K} \rightarrow 5$ bar/298 K). Figures 2 b-2f show the gravimetric and volumetric $\mathrm{H}_{2}$ deliverable capacities; the raw data is available in a dynamic visualization tool at: https://aam.ceb.cam.ac.uk/mofexplorer.html. Part 1 of the tool contains the data for purely cryogenic $\mathrm{H}_{2}$ delivery, whereas Part 2 contains the data for near ambient $\mathrm{H}_{2}$ delivery. Under cryogenic conditions and high pressure (100 bar/77 K), benchmark MOFs such as MOF-5, IRMOF-20, NU-1500-Al, IRMOF-10, and NU-1501-Al get the highest values in terms of both gravimetric and volumetric deliverable capacity (Fig. 2b). Interestingly, as the storage pressure decreases (Fig. 2c and Fig. 2d), denser MOFs with open metal sites such as HKUST1 and $\mathrm{Ni}(\mathrm{dobdc})$ begin to match and outperform large gravimetric surface area materials under volumetric conditions; the deliverable capacities of $\mathrm{H}_{2}$ for HKUST-1 display $c a$. $10 \%$ reduction when the storage pressure is reduced from 100 bar to 25 bar at $77 \mathrm{~K}$. At near ambient conditions, HKUST1 and $\mathrm{Ni}_{2}$ (dobdc) outperformed all the other benchmark materials in terms of volumetric deliverable capacity. The exceptional performance of HKUST-1 and $\mathrm{Ni}_{2}$ (dobdc) can be attributed to the denser crystal structure and high density of unsaturated metal centres, which give way to enhanced adsorbate-adsorbent interactions. The results of the HTS suggest that higher surface areas and large pore volumes give way to exceptional $\mathrm{H}_{2}$ deliverable capacities at low temperatures and high pressures. Conversely, and as expected, denser structures and stronger adsorbent-adsorbate interactions give way to enhanced $\mathrm{H}_{2}$ deliverable capacities at lower pressures and higher temperatures $(12,23,26)$. 

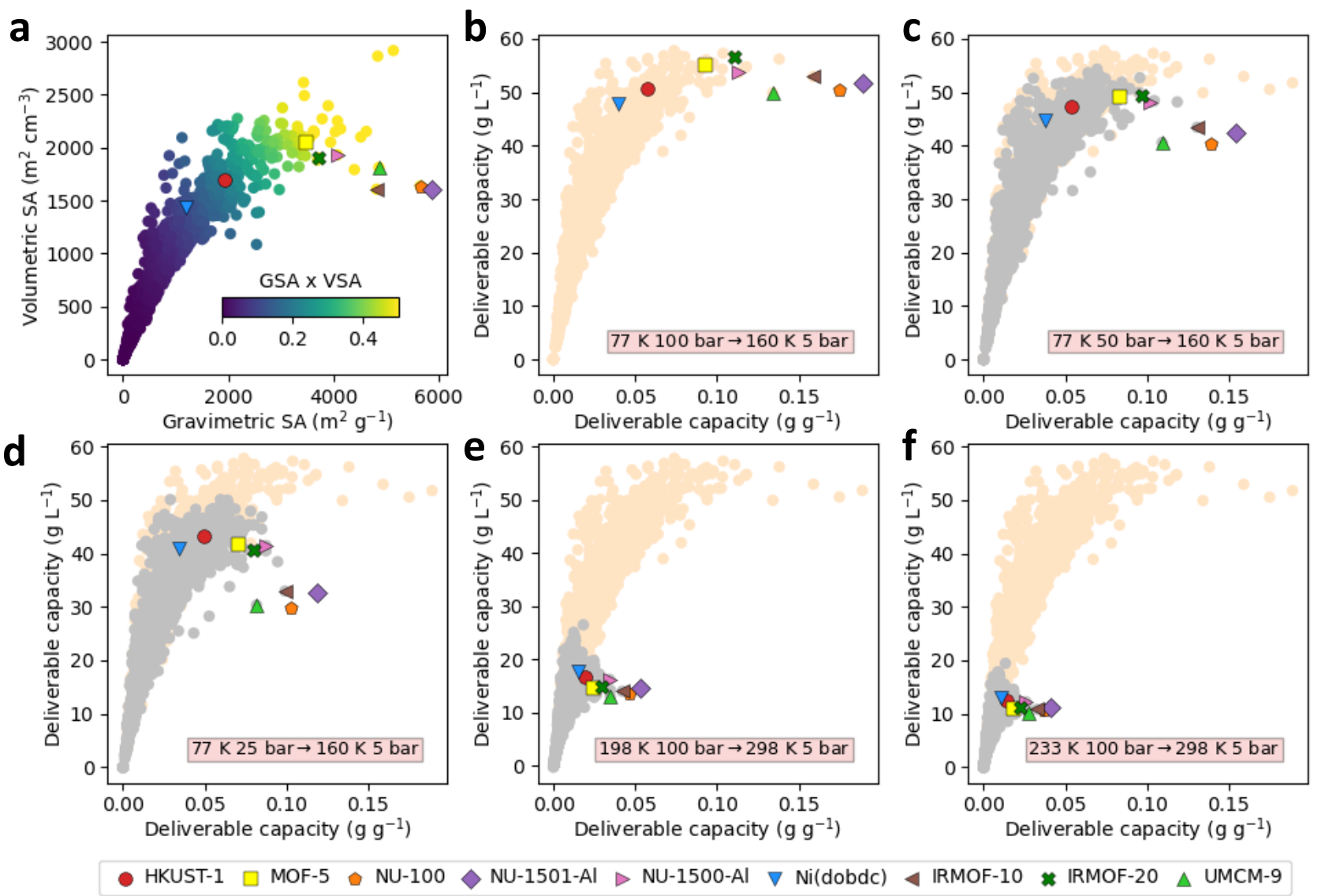

Fig. 2. Computational Screening of Benchmark MOF Materials. a, Relationship between volumetric and gravimetric BET areas for 2940 MOFs. b, Hydrogen volumetric and gravimetric deliverable capacities for a combined temperature-pressure $\mathrm{H}_{2}$ delivery system $(100 \mathrm{bar} / 77 \mathrm{~K} \rightarrow 5 \mathrm{bar} / 160 \mathrm{~K})$. c, Hydrogen volumetric and gravimetric deliverable capacities for a combined temperature-pressure $\mathrm{H}_{2}$ delivery system $(50 \mathrm{bar} / 77 \mathrm{~K}$ $\rightarrow 5 \mathrm{bar} / 160 \mathrm{~K})$. d, Hydrogen volumetric and gravimetric deliverable capacities for a combined temperaturepressure $\mathrm{H}_{2}$ delivery system $(25 \mathrm{bar} / 77 \mathrm{~K} \rightarrow 5 \mathrm{bar} / 160 \mathrm{~K}$ ). e, Hydrogen volumetric and gravimetric deliverable capacities for a combined temperature-pressure $\mathrm{H}_{2}$ delivery system $(100 \mathrm{bar} / 198 \mathrm{~K} \rightarrow 5 \mathrm{bar} / 298 \mathrm{~K})$. f, Hydrogen volumetric and gravimetric deliverable capacities for a combined temperature-pressure $\mathrm{H}_{2}$ delivery system $(100 \mathrm{bar} / 233 \mathrm{~K} \rightarrow 5 \mathrm{bar} / 298 \mathrm{~K})$. Peach coloured points in $\mathbf{b}$ to $\mathbf{f}$ represent $\mathrm{H}_{2}$ performance for a 100 $\mathrm{bar} / 77 \mathrm{~K} \rightarrow 5 \mathrm{bar} / 160 \mathrm{~K}$ system, grey points represent $\mathrm{H}_{2}$ performance for the named system for $\mathbf{c}$ to $\mathbf{f}$.

Once the HTS data has been collected, we moved to a principal component analysis (PCA). Commonly used for dimensionality reduction, PCA helps to choose the minimum number of variables needed to explain the maximum amount of variance in the dataset. The raw data for the PCA is available in the dynamic PCA visualization tool at https://hydrogen-storage-pca.herokuapp.com. The supplementary information (Fig. S8-S10 \& Table S7) provides more details about the geometric properties' calculation, HTS studies, and PCA. From there, we were able to extract the following key insights: (i) one should focus on optimizing the density of the material along with selecting an appropriate adsorption pressure for the process, and (ii) there exists an upper limit for the adsorption pressure, in the range of 50-55 bar, beyond which the pressure starts to negatively influence the performance of the material. These two conclusions are not a surprise. Indeed, while it is clear that 
densification is key for the deployment of MOFs (15), it is also well known that the excess capacity reaches a maximum and then declines with increasing pressure because it becomes more efficient to pack molecules in the gas phase than on the surface (27).

\section{Synthesis and Characterisation}

Based on the HTS and PCA, we selected HKUST-1. Not only its predicted volumetric absolute and deliverable capacities are high but, looking at the industrial production, it is based on a commercially available organic ligand and a simple synthesis process. In addition to standard synthetic methods, HKUST-1 can be made through spray-drying (28) and mechanosynthesis (29). Here, we performed the synthesis of HKUST-1 not as a powder, but as a high-density monoHKUST-1 using the previously reported sol-gel method (17). After the formation of the crystalline primary MOF particles at the beginning of the reaction, the mother solution was centrifuged, and the resulting MOF gel was washed to remove unreacted precursors. After three washing steps, the MOF gel was then allowed to dry overnight at room temperature resulting in the formation of monoHKUST-1. Figure 3a displays an optical image of monoHKUST-1, while Figure S1 displays the powder X-ray diffraction (PXRD) patterns of the material. Once the monoHKUST-1 is dry, activation was carried out by heating to 120 ${ }^{\circ} \mathrm{C}$ under vacuum for $12 \mathrm{~h}$. The monoHKUST-1 retains the macroscopic monolithic morphology and shape of the mould after activation. We obtained the envelope and particle packing densities of the monolithic and powdered materials, respectively, using mercury intrusion porosimetry (Fig. S26). The measured envelope density of monoHKUST-1 is in agreement with the previously reported data, with an overall density of $1.07 \mathrm{~g} \mathrm{~cm}^{-3}$ (17), and verified by Particle Authority as a part of NREL $\mathrm{H}_{2}$ capacity characterization. We then evaluated the porosity using $\mathrm{N}_{2}$ adsorption at $77 \mathrm{~K}$ (Fig. 3b \& Fig. S2-S3). Table S19 compares the densities, gravimetric and volumetric Brunauer, Emmett and Teller (BET) areas - calculated using Rouquerol's updated criteria implemented in BETSI (Fig. S4-S5) (30) - and pore volumes of monoHKUST-1 with those of powder and densified benchmark MOF materials. While monoHKUST-1 displays one of the lowest observed gravimetric BET areas $\left(1,552 \mathrm{~m}^{2} \mathrm{~g}^{-1}\right)$ and total pore volume $\left(0.634 \mathrm{~cm}^{3} \mathrm{~g}^{-1}\right)$ of the materials presented, the critical advantage of the monolithic MOF is the high bulk density which enables benchmark volumetric performance (BET area $=1,651$ $\mathrm{m}^{2} \mathrm{~cm}^{-3}$; pore volume $=0.675 \mathrm{~cm}^{3} \mathrm{~cm}^{-3}$ ) which far exceeds those of powdered and mechanically pressed MOF counterparts (Table S19 \& Fig. S46) $(12,16,31)$. The measured bulk density of monoHKUST-1 $\left(1.07 \mathrm{~g} \mathrm{~cm}^{-3}\right)$ is higher than the crystal densities of HKUST-1 $\left(0.883 \mathrm{~g} \mathrm{~cm}^{-3}\right)$, which can be attributed to the presence of amorphous, denser phases within the monolithic material (17). Similar observations of high bulk density retention leading to high microporosity have been seen for previously studied monoZIF-8 and monoUiO-66 (20, 21). 
a

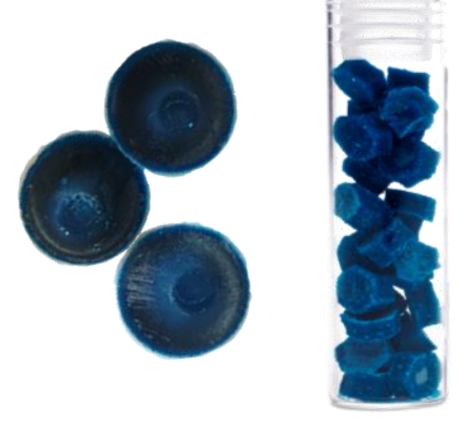

d

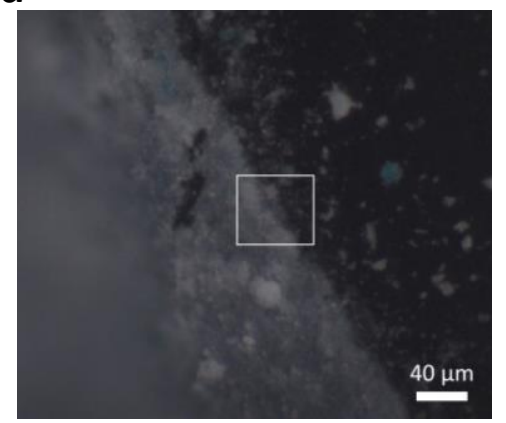

b

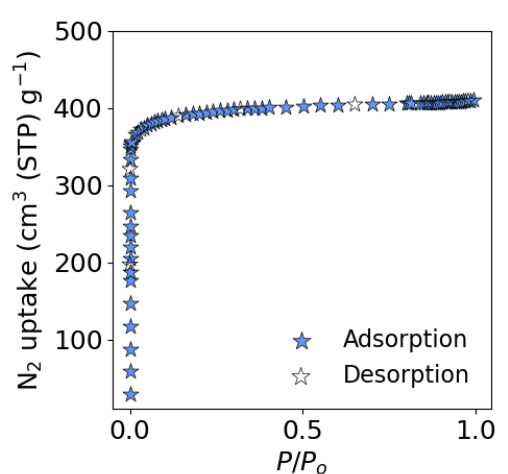

e

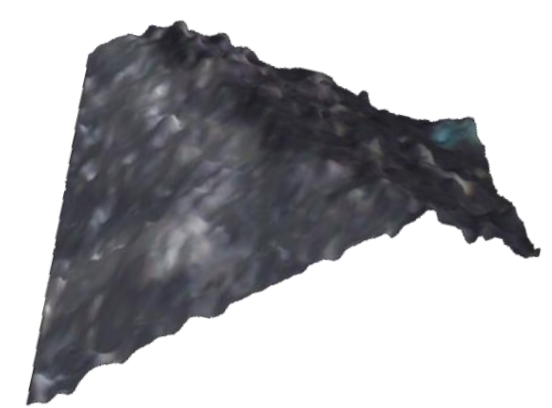

C

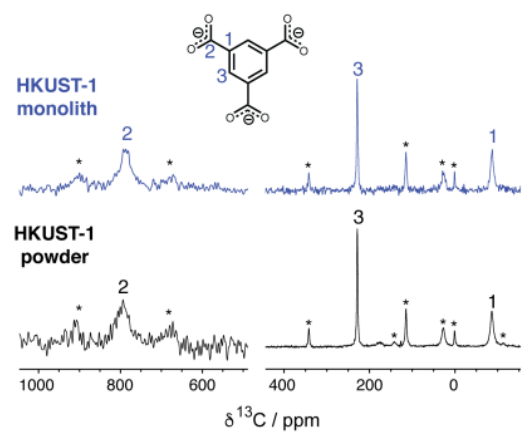

f

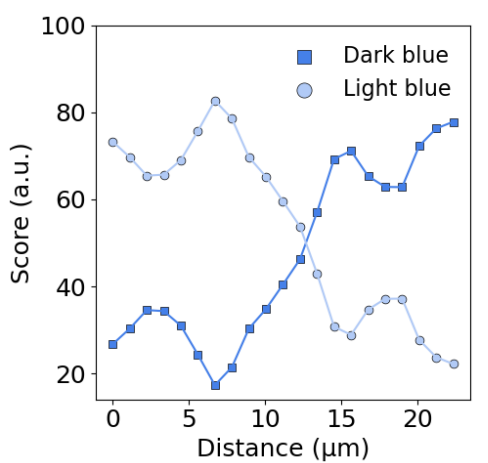

Fig. 3. Characterisation, Nuclear Magnetic Resonance (NMR) spectroscopy and Raman microscopy studies of pristine monoHKUST-1. a, optical images of monoHKUST-1 prepared via traditional (Left) and scaled-up synthesis (Right). b, linear plot of $77 \mathrm{~K} \mathrm{~N}$ adsorption isotherm for monoHKUST-1. c, ${ }^{13} \mathrm{C}$ NMR spectra of monoHKUST-1 and HKUST-1 powder samples. $\mathbf{d}$, optical image and $\mathbf{e}$, 3-dimensional reconstruction of the monoHKUST-1 section mapped by Raman microscopy, f, showing the corresponding normalised classic least squares (CLS) scores, associated with Raman spectra of the dark blue and light blue portions over the mapped section.

Aiming to see if there are any structural or chemical differences between the powder and monolithic materials, we first examined the local environment of ${ }_{m o n o}$ HKUST-1 using NMR spectroscopy. The ${ }^{13} \mathrm{C}$ NMR spectra (Fig. 3c) for monoHKUST-1 and HKUST-1 powder show similar peak assignments (Table S18) to those previously reported in the literature for HKUST-1 (32), with no additional local environments observed for the $\mathrm{BTC}^{3-}$ linker $\left(\mathrm{BTC}^{3-}=1,3,5-\right.$ benzenetricarboxylate) in any sample. These results suggest, therefore, that the local chemical environment of the linker molecule in the powder and monolith materials is very similar at the bulk level. To further examine the local environment, we analysed monoHKUST-1 using Raman microscopy. Raman spectra were initially collected by focusing on two independent regions of the monolithic sample corresponding to the lighter and darker blue sections, respectively, as seen using optical microscopy (Fig. 3d \& Fig. S33-S35); Figure S36 shows the Raman spectra for both sections. The dark blue regions display a spectrum that was found to be similar to previous reports on HKUST1 (33), whereas the lighter blue region contains additional peaks that can be attributed to BTC $^{3-}$ hydrates and copper paddlewheel hydration. When the Raman mapping was performed (Figs. 3e, f), by monitoring the normalised scores obtained from classic least squares (CLS) regression analysis, 
fitting the full spectra obtained from the dark and light blue regions of the mono $_{0}$ HKUST-1 material, we can see a clear trend. Here, the spectrum associated with HKUST-1 becomes dominant as the Raman probe moves from the lighter blue to the darker blue section.

We further probed the structural heterogeneity of monoHKUST-1 using synchrotron X-ray scattering experiments across multiple length scales, using small-angle X-ray scattering (SAXS), pair distribution function (PDF) and X-ray diffraction (XRD). We used SAXS (Figs. S31) to determine the size of the primary MOF particles for both monolithic and powdered HKUST-1. Interestingly, while the monoHKUST-1 sample contains primary particles with a spherical diameter of $c a .20 \mathrm{~nm}$ (Fig. S32), the powdered HKUST-1 sample was found to contain two broader distributions, with particles of $c a .24$ to $92 \mathrm{~nm}$ in diameter. To evaluate the uniformity of the monolith, we sectioned the monoHKUST-1 samples into ca. $1 \mathrm{~mm}$ segments (Fig. S27) and mapped them in two dimensions with $500 \mu \mathrm{m}^{2}$ resolution (Fig. 4a). Diffraction patterns revealed differences in the scattering data collected from probe volumes at the external surface of the monolith (Fig. $\mathbf{4 b}, \mathbf{c}$ ). To compare the relative presence of impurities, the normalized integral intensity of the spurious diffraction peak at $\mathrm{Q}=0.83$ $\AA^{-1}$ and the (222) peak $\left(\mathrm{Q}=0.83 \AA^{-1}\right)$ of HKUST-1 were fitted using the cumulative trapezoid method as implemented in the Python package scipy.integrate (Fig. 4e-4h). To further probe the monolithic HKUST-1 PDF, we analyzed the data using previously described non-negative matrix factorization (NMF) techniques (34). Two components were used to describe the data (Fig. 4d, 4i-4l \& Fig. S29). Comparison of these maps (Fig. S30) reveals reasonable corroboration between the PDF-NMF components and the spurious diffraction peaks observed, with component A having a mean Pearson correlation of 0.92 with the (222) peak of Slice 1 and 0.98 with the (222) peak of Slice 2, and component B having a mean Pearson correlation of 0.78 with the spurious peak of Slice 1 and 0.91 with the spurious peak of Slice 2. Diffractograms collected in this region included additional peaks consistent with those previously ascribed to hydrolytic decomposition of HKUST-1 (35) (Fig. 4l). In contrast, the centre of the monolith samples exhibited little to no presence of these peaks (Fig. $\mathbf{4 j}$ ) and were fitted well with an HKUST-1 model without evidence of impurities. Indeed, this mapping matches with an observed difference in colour between the centre (dark blue) and edge (light blue) of the sample. Taking into account the above observations on Raman scattering, this further suggests the existence of HKUST-1 and a hydrated form, respectively (33). An analysis of the PDF data decomposed the data into two phases that correlate well to the distribution of HKUST-1 and the additional diffraction peaks. The PDF component corresponding to additional diffraction peaks exhibits limited radial distance atom-atom correlations with the exception of an increase in $\mathrm{Cu}-\mathrm{Cu}$ distances, consistent with the hydration of the paddlewheel (Fig. S30). It is remarkable that densification of the material in monoHKUST-1 not only improves volumetric adsorption but may also 
improve the hydrolytic stability of the material by limiting accessible surfaces to the outer edges of the monolith. The hydration of the $\mathrm{Cu}$ paddlewheels on the outer surfaces of monoHKUST-1 may act in a "sacrificial" manner similar to those observed for STAM-17-OEt, enabling the retention of the bulk porosity upon exposure to moisture (36). This was confirmed using $77 \mathrm{~K} \mathrm{~N}_{2}$ adsorption isotherms which were performed on a monoHKUST-1 sample stored at room temperature for 18 months. This sample was found to retain over $90 \%$ of its overall BET area and porosity after 18 months of storage (Fig. S48). The monolithic nature was found to significantly improve the chemical

a
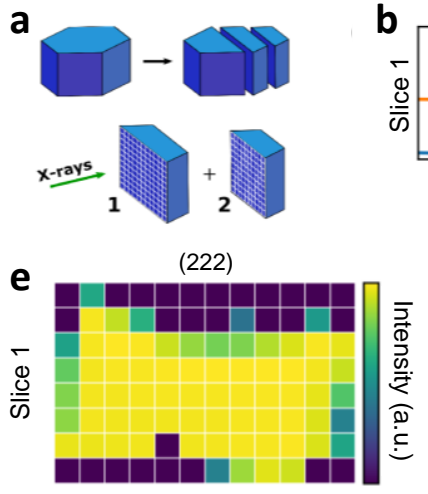

i

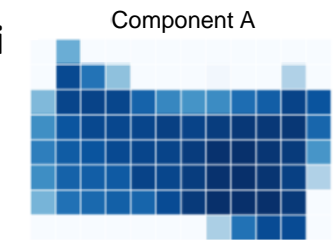

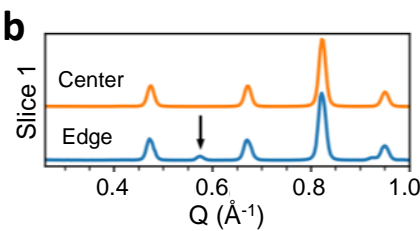

$Q \approx 0.57 \AA^{-1}$
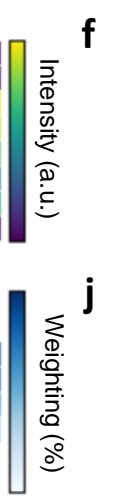

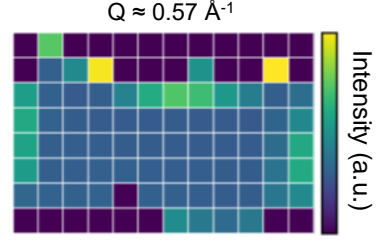

Component B

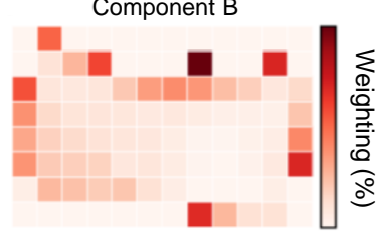

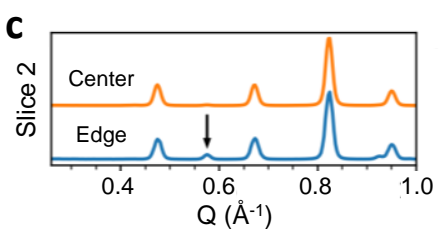

(222)

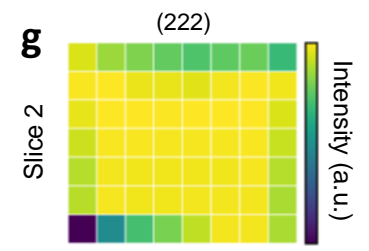

Component A

k

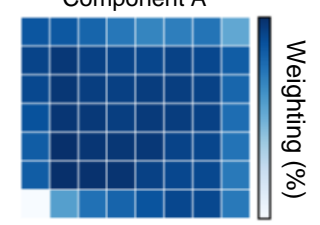

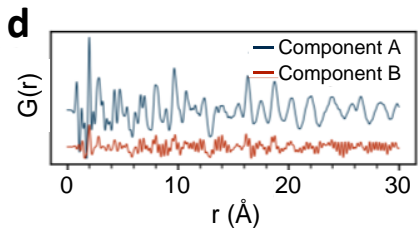

$\mathbf{h}$

$Q \approx 0.57 \AA^{-1}$

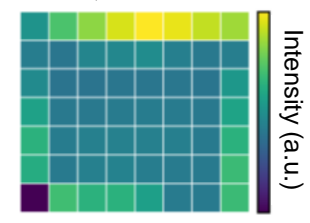

Component B

I

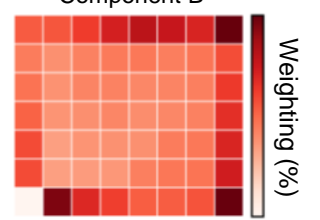

Fig. 4. Mapping X-ray diffraction and Pair Distribution (PDF) studies for monoHKUST-1. a, Monolithic samples were segmented into slices, and X-rays were used to map their cross-sections. b, c powder X-ray diffraction patterns collected at the edge (blue) and centre (orange) of slices 1 and 2, respectively. Patterns collected at the edge exhibit spurious peaks at $Q \approx 0.57 \AA^{-1}$ (noted with black arrow) as well as at $0.93 \AA^{-1}$. For comparison, the integral intensity of the (222) peak of HKUST-1 $\left(Q \approx 0.83 \AA^{-1}\right)$ is mapped for each slice (e and $\mathbf{g}$, respectively) as well as the integral intensity of the peak at $Q \approx 0.57 \AA^{-1}$ (f and $\mathbf{h}$, respectively). $\mathbf{d}$, PDF components derived from non-negative matrix factorization of all total scattering mapping data; the fractional weighting of components A (i, k) and B (j, l) are mapped to depict their distribution across the monolith.

\section{Hydrogen Storage Performance}

To probe the improved performance of densified MOFs in $\mathrm{H}_{2}$ storage, we collected high-pressure adsorption isotherms at eight temperatures, from 75.6 to $303 \mathrm{~K}$, and up to 140 bar (Fig. 5 and S12S15) on monoHKUST-1. To ensure reproducibility of the data, this was done in three separate laboratories: NREL, University of Alicante and University of Cambridge. It is important to note that the experimentally measured values are excess amounts adsorbed $\left(N_{\text {exc }}\right)$, which were then transformed into absolute uptakes ( $N_{\text {abs }}$ ) by using Equation (1) (Supporting Information, Equation 5):

$$
N_{a b s}=N_{e x c}+\rho V_{\text {pore }}
$$


295 where $\rho$ is the density of the gas at the given adsorption pressure and temperature, obtained from the 296 National Institute of Standards and Technology (NIST) (37), and $V_{\text {pore }}$ is the pore volume of the 297 adsorbent (27). The calculated absolute adsorption ( $\left.N_{\mathrm{abs}}\right)$ (Supporting Information, Equation 5) based 298 on excess $\left(N_{\text {exc }}\right) \mathrm{H}_{2}$ isotherms collected at 75.6, 77 and $77 \mathrm{~K}$ (Fig. 5a \& S14-S15) at NREL, the 299 University of Cambridge and the University of Alicante, respectively, were found to be in good 300 agreement, displaying similar $\mathrm{H}_{2}$ uptakes at corresponding pressures for each of the three isotherms. 301 Fig. S12-S13 displays the NREL excess and calculated total $\left(N_{\text {tot }}\right)$ (Supporting Information, Equation 302 6) $\mathrm{H}_{2}$ uptakes at 75.6 and $303 \mathrm{~K}$ for comparison $(38-40)$. Figure $5 \mathbf{b}$ shows the absolute $\left(N_{\mathrm{abs}}\right)$ 303 volumetric adsorption isotherms of $\mathrm{H}_{2}$ at $75.6 \mathrm{~K}$ in mono HKUST-1 compared with a densified HKUST3041 powder and a simulated $\mathrm{H}_{2}$ isotherm for HKUST-1. The difference between isotherms is striking; 305 interestingly, mono HKUST-1 displays higher $\mathrm{H}_{2}$ uptake at lower pressures compared to the densified 306 powder sample, achieving a saturation uptake of $c a .46 \mathrm{~g} \mathrm{~L}^{-1}$ at 50 bar. In comparison, the densified 307 HKUST-1 powder achieves an uptake of only ca. $28 \mathrm{~g} \mathrm{~L}^{-1}$ at $50 \mathrm{bar}$, and $c a .38 \mathrm{~g} \mathrm{~L}^{-1}$ at 100 bar. In 308 comparison, the simulated absolute $\mathrm{H}_{2}$ uptake of an HKUST-1 ( $\left.c a .45 \mathrm{~g} \mathrm{~L}^{-1}\right)$ and the monoHKUST-1 309 isotherms display similar features. The higher uptake of monoHKUST-1 compared to the simulated 310 isotherm can be attributed to the envelope density observed in monoHKUST-1 (1.07 $\left.\mathrm{g} \mathrm{cm}^{-3}\right)$, which 311 exceeds the theoretical crystal density for HKUST-1 $\left(0.883 \mathrm{~g} \mathrm{~cm}^{-3}\right)$. 
a
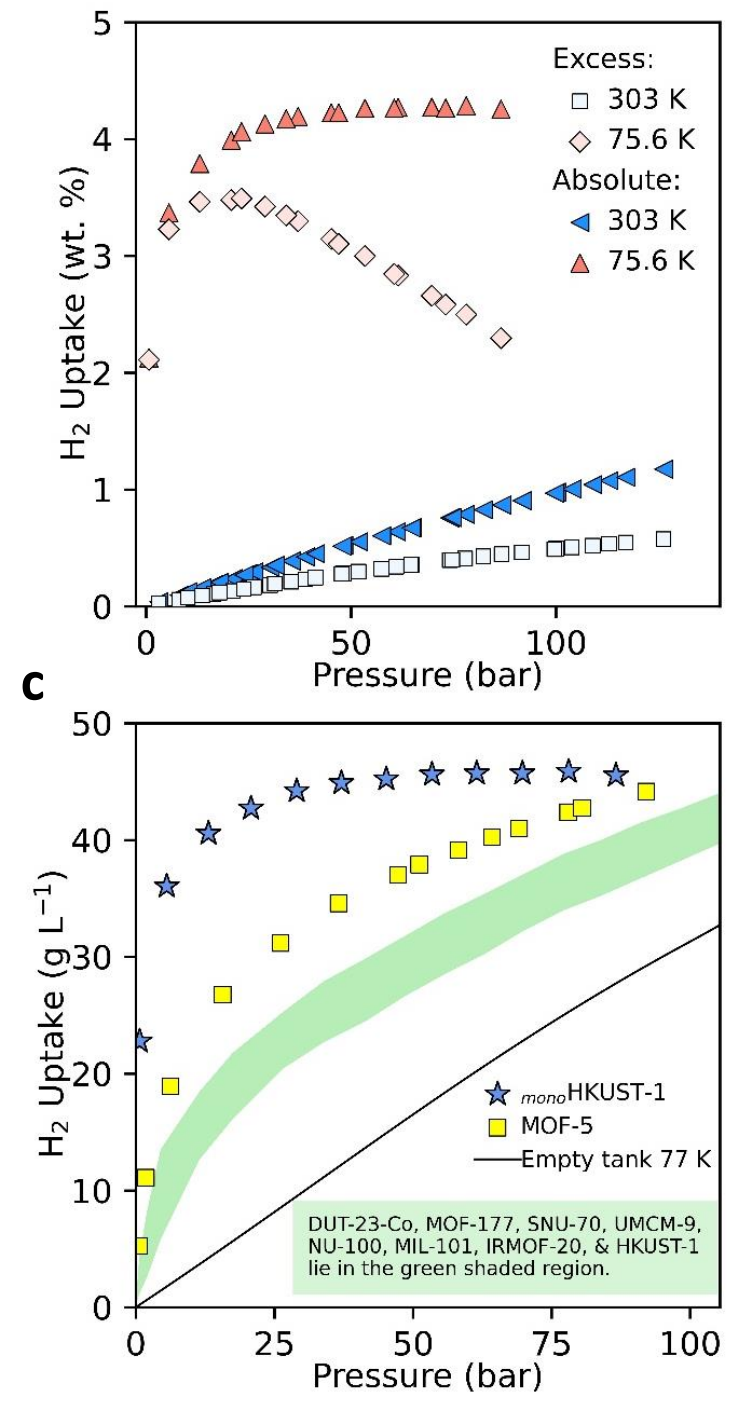

b
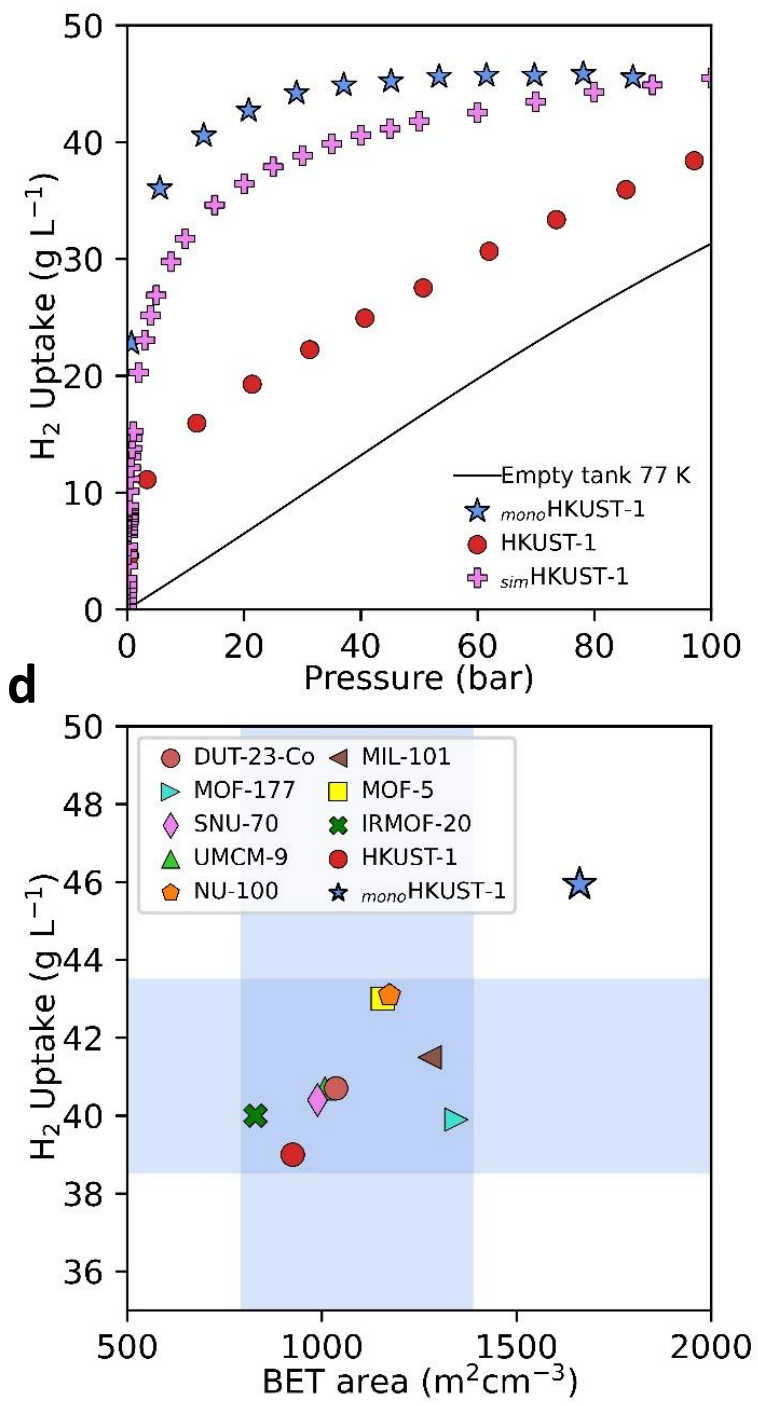

Fig. 5. $\mathrm{H}_{2}$ Adsorption Isotherms of Densified and Monolithic MOF Materials. a, Excess and total ( $\left.N_{\text {abs }}\right)$ $\mathrm{H}_{2}$ adsorption isotherms for monoHKUST-1 measured at $75.6 \mathrm{~K}$ (liquid nitrogen measurement made at the National Renewable Energy Laboratory, elevation 5768 feet $(1758 \mathrm{~m})$ ) and $303 \mathrm{~K}$. An envelope density of $1.07 \mathrm{~g} \mathrm{ml}^{-1}$ was used to calculate the volumetric $\mathrm{H}_{2}$ uptake of the monoHKUST-1 material. b, high-pressure absolute $\left(N_{\text {abs }}\right) \mathrm{H}_{2}$ isotherms of monoHKUST-1 compared to pressed HKUST-1 powder and simulated HKUST1 uptake at $77 \mathrm{~K}$. c, $77 \mathrm{~K} \mathrm{H}_{2}$ adsorption isotherms of monoHKUST-1 and previously reported densified MOFs

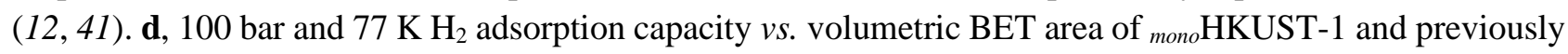
reported benchmark densified MOF materials $(12,41)$.

Figure 5c compares the volumetric $\mathrm{H}_{2}$ adsorption performance of monoHKUST-1 with the performance of previously reported densified MOF materials (Fig. S41) using real bulk densities of the materials $(12,13,31,41-44)$; Figure S40 compares the performance of monoHKUST-1 with the performance of previously reported benchmark MOF materials, with the caveat that this is done based on theoretical single-crystal density $(10,24,25,45,46)$. Importantly, a densified powder, as described above, will be many times limited to a density $50 \%$ lower than the theoretical crystal density $(12,16)$. Although the gravimetric $\mathrm{H}_{2}$ uptake of monoHKUST-1 is lower than all the previously reported materials studied herein (Table S19), the monoHKUST-1 material displays benchmark volumetric $\mathrm{H}_{2}$ 
adsorption performance. The closest material to monoHKUST-1 in terms of performance is MOF-5, displaying a $\mathrm{H}_{2}$ adsorption capacity of $c a .43 \mathrm{~g} \mathrm{~L}^{-1}$ at 100 bar. The performance of monoHKUST-1 was also found to outperform the benchmark carbon-based material AX21 at 100 bar and $77 \mathrm{~K}$ (Table

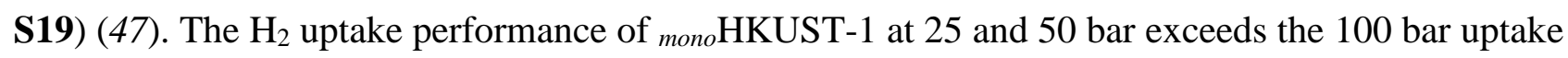
of the densified powder MOFs (Table S19, Fig. 5c \& Fig. S42). The exceptional performance of the monoHKUST-1 sample is attributed to the high bulk density achieved via a sol-gel synthesis approach, overcoming the lower densities and mechanical degradation issues associated with traditional powder pressing techniques $(12,16)$. The effects of mechanical pressing of MOFs have a detrimental impact on the overall $\mathrm{H}_{2}$ adsorption performance for storage applications $(12,16)$. For conformed, pressedpowder materials, $\mathrm{H}_{2}$ excess adsorption capacities are generally retained up to a point where the density is increased up to $c a$. $50 \%$ of the single-crystal density (Fig. S47). After that point, although the density continues increasing, the maximum excess adsorption value starts to decrease due to the continued mechanical collapse of the $\operatorname{MOF}(12,16)$. In contrast, the monoHKUST-1 sample was found to retain a high $\mathrm{H}_{2}$ adsorption capacity at bulk densities exceeding those of the crystal density of HKUST-1 (i.e. $1.07 \mathrm{~g} \mathrm{~cm}^{-3}$ vs. $0.883 \mathrm{~g} \mathrm{~cm}^{-3}$ ). As has been seen elsewhere, the high-pressure $\mathrm{H}_{2}$ adsorption performance of the densified MOFs was found to follow a similar trend to those of the volumetric BET areas of the materials studied (Fig. 5d) (12, 25). This means that volumetric BET area, using an appropriate density, is a valuable descriptor to predict the volumetric performance of MOFs.

To determine the adsorbate-adsorbent interaction energies for monoHKUST-1, we calculated the isosteric heats of adsorption $\left(Q_{\mathrm{st}}\right)$ from $\mathrm{H}_{2}$ isotherms collected at eight temperatures using the Virial

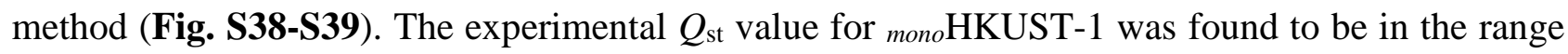
of 3.7-5.5 kJ mol${ }^{-1}$. This value was found to be consistent with previously reported values for HKUST-1 in addition to other benchmark copper paddlewheel MOFs (NOTT-112 and NU-125) (25). $Q_{\text {st }}$ is an important variable in understanding how easy it is to release the gases at lower pressures and/or higher temperatures. Indeed, the storage and release temperatures are another key factor for $\mathrm{H}_{2}$ storage materials. Since the current DOE targets only address hydrogen delivery temperature (-40 to $85{ }^{\circ} \mathrm{C}$, to meet fuel cell system operation specifications) and not the storage system operating temperature, a range of possible system designs can be considered. To assess the performance of monoHKUST-1 over a wide range of temperatures, we applied the dual-process Langmuir (DPL)(48) equation to the experimental isotherms (Fig. S16-S25). We found the DPL equation to be in good agreement with the experimental data collected at eight temperatures. The initial conditions assessed for storage of $\mathrm{H}_{2}$ were near ambient $\left(-75\right.$ to $\left.100^{\circ} \mathrm{C}\right)$ up to 100 bar (Fig. 6a \& Table S21). monoHKUST1 displays a $\mathrm{H}_{2}$ adsorption capacity of $10.1 \mathrm{~g} \mathrm{~L}^{-1}$ at $25^{\circ} \mathrm{C}$ and $100 \mathrm{bar}$, which is, to the best of our knowledge, the highest measured $\mathrm{H}_{2}$ capacity of a densified MOF - using real MOF density - under 
364 these conditions. The usable capacity in this case, with no temperature swing, is slightly reduced to $3659.3 \mathrm{~g} \mathrm{~L}^{-1}$, however, due to the uptake of $0.84 \mathrm{~g} \mathrm{~L}^{-1}$ at 5 bar. This still outperforms compressed 366 hydrogen, which would require compression to over 150 bar to obtain the same total volumetric 367 usable capacity at $25^{\circ} \mathrm{C}\left(\right.$ Fig. 6b). At 100 bar and a temperature of $-75^{\circ} \mathrm{C}$, monoHKUST-1 takes up a 368 total of $16.5 \mathrm{~g} \mathrm{~L}^{-1} \mathrm{H}_{2}$, which corresponds to a total usable capacity of $14.8 \mathrm{~g} \mathrm{~L}^{-1}$. If the use of a 369 temperature swing in a storage system is considered, through application of active cooling at high 370 filling levels, the usable capacities attained with monoHKUST-1 are even higher. For example, 371 adsorption at $-40{ }^{\circ} \mathrm{C}$ and desorption at $25^{\circ} \mathrm{C}$ affords a usable capacity of $12.4 \mathrm{~g} \mathrm{~L}^{-1}$. A temperature 372 swing from adsorption at $-75^{\circ} \mathrm{C}$ to desorption at $25^{\circ} \mathrm{C}$ gives a usable capacity of $15.7 \mathrm{~g} \mathrm{~L}^{-1}$. This 373 usable capacity represents the highest $\mathrm{H}_{2}$ volumetric usable capacity achieved to date for a densified 374 adsorbent operating in this temperature range. Although these values are comparable to the current 375 theoretical benchmarks $\left(\mathrm{Ni}_{2}(\mathrm{dobdc})\right.$, MOF-5 and $\mathrm{V}_{2} \mathrm{Cl}_{2.8}($ btdd $\left.)\right)(10,49)$ under these conditions 376 (Table S21), it is important to highlight that these previous values are based on theoretical crystal 377 densities and not experimental envelope densities, as reported here for monoHKUST-1. A natural 378 assumption is to expect a $c a .50 \%$ reduction of the density and therefore volumetric capacities in densified 379 powders $(12,16)$ 
a

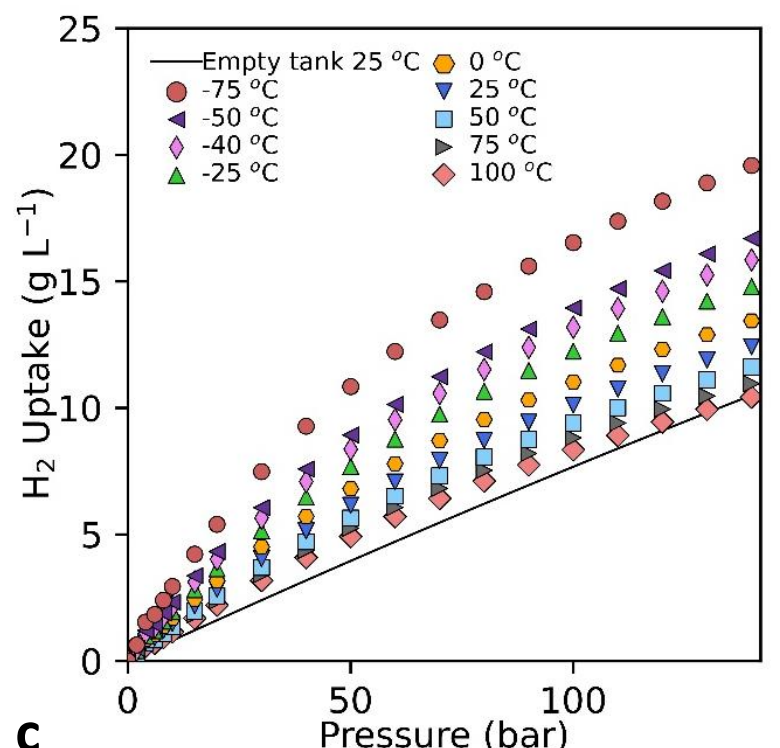

c

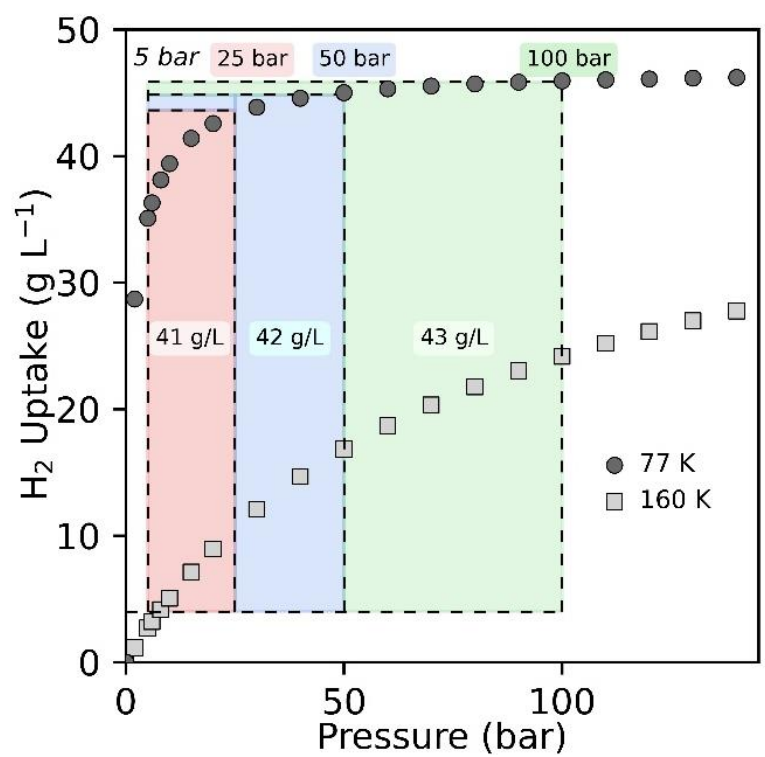

b
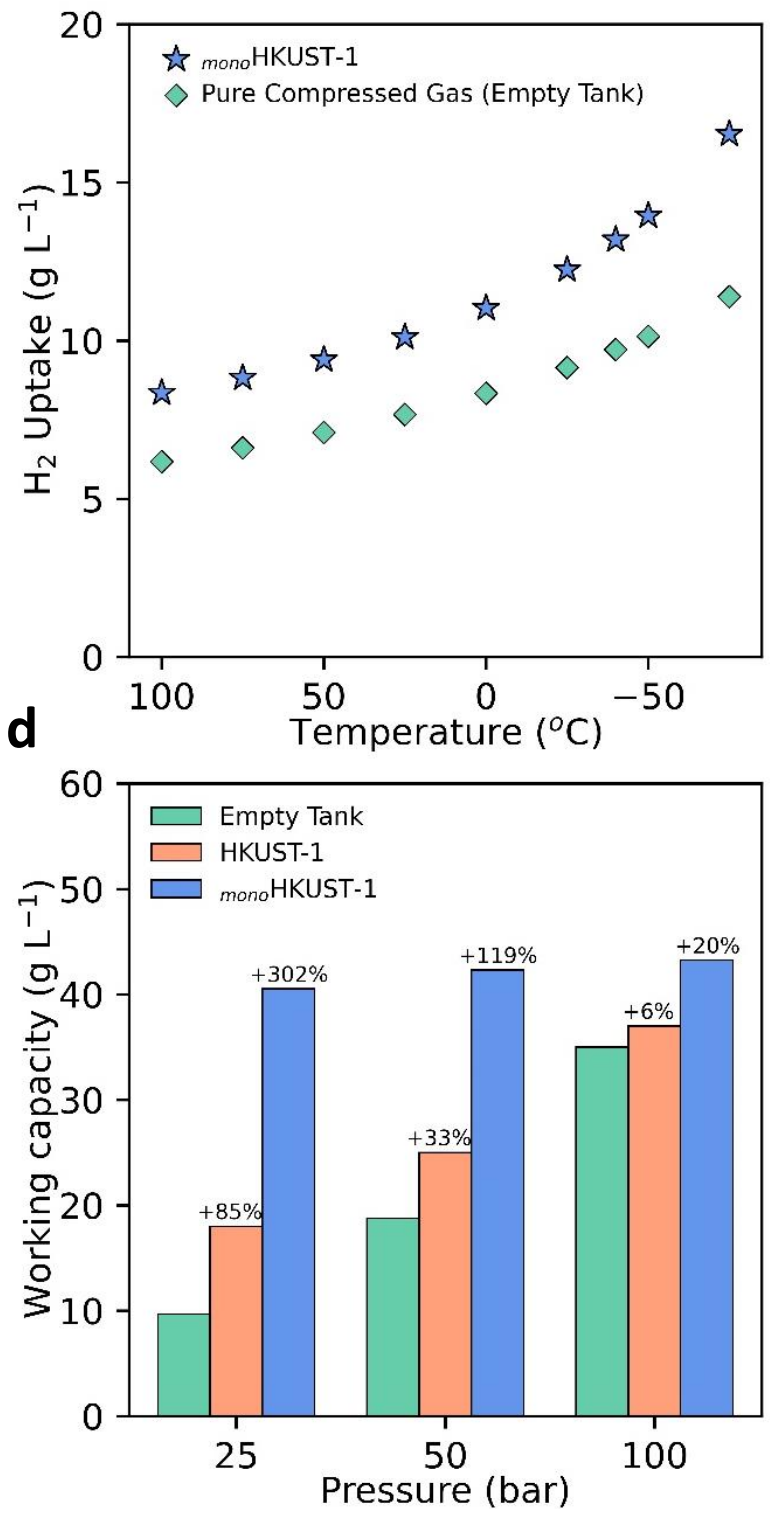

Fig. 6. mono HKUST-1 $\mathrm{H}_{2}$ Storage Working Capacities. a, near-ambient $\mathrm{H}_{2}$ adsorption isotherms for monoHKUST-1 compared to compressed $\mathrm{H}_{2}$ gas at $25^{\circ} \mathrm{C}$. b. gas storage performance at 100 bar of monoHKUST1 compared to compressed gas at near ambient temperatures. c, cryogenic $\mathrm{H}_{2}$ gas delivery for temperaturepressure swing (100 bar/77 K $\rightarrow 5 \mathrm{bar} / 160 \mathrm{~K}$ ) storage system. d, $\mathrm{H}_{2}$ working capacity of monoHKUST-1 compared to HKUST-1 powder and an empty tank at various adsorption pressures at $77 \mathrm{~K}$.

When cryogenic conditions are employed for $\mathrm{H}_{2}$ storage, the use of a temperature swing step (i.e. 77 to $160 \mathrm{~K}$ ) can increase the usable capacities by increasing the quantity of $\mathrm{H}_{2}$ desorbed upon cycling. While monoHKUST-1 displays an overall $\mathrm{H}_{2}$ uptake of $46.0 \mathrm{~g} \mathrm{~L}^{-1}$ at $100 \mathrm{bar}$ and $77 \mathrm{~K}$, the high $\mathrm{H}_{2}$ uptake at low pressures limits the working capacity to $11.2 \mathrm{~g} \mathrm{~L}^{-1}$. When a combined temperature-pressure swing system $(100 \mathrm{bar} / 77 \mathrm{~K} \rightarrow 5 \mathrm{bar} / 160 \mathrm{~K})$ is employed, the working capacity increases to $43.3 \mathrm{~g} \mathrm{~L}^{-1}$ (Fig. 6c). This exceeds the performance of all densified MOF benchmarks under similar conditions (Table S20) (12). Although, a priori, this may sound contrary to the results obtained from the HTS, here it is important to point out that the force fields used in simulations tend 
to under-predict the $\mathrm{H}_{2}$ uptake for MOFs containing open-metal sites - including benchmark MOFs such as HKUST-1, NU-100, Ni(dobdc) and MIL-101 considered in this study - particularly at low pressures where the polarization can play a significant role in the $\mathrm{H}_{2}$ adsorption (50). Also, the structures used in silico are perfect single crystals and do not contain defects such as missing linkers, missing clusters, etc. commonly seen in experimental structures. Combined, this can lead to differences between experimentally determined and theoretical deliverable capacities. Interestingly, the monoHKUST-1 sample reaches $>95 \%\left(43.8 \mathrm{~g} \mathrm{~L}^{-1}\right)$ saturation at $25 \mathrm{bar}$, enabling $\mathrm{H}_{2}$ saturation at much lower pressures compared to many benchmark MOFs. When lower adsorption pressures are taken into account (Fig. 6d), monoHKUST-1 exhibits working capacities of 42.3 and $40.5 \mathrm{~g} \mathrm{~L}^{-1}$, for loading pressures of $50(50 \mathrm{bar} / 77 \mathrm{~K} \rightarrow 5 \mathrm{bar} / 160 \mathrm{~K})$ and $25 \mathrm{bar}(25 \mathrm{bar} / 77 \mathrm{~K} \rightarrow 5 \mathrm{bar} / 160 \mathrm{~K})$, respectively. These values represent a $302 \%$ and $119 \%$ increase on the $\mathrm{H}_{2}$ volumetric storage capacities of an empty tank at 25 and 50 bar, respectively. By comparison, under ambient temperatures, $\mathrm{H}_{2}$ gas would need to be pressurised to 145 and 700 bar at 77 and $298 \mathrm{~K}$, respectively, to achieve similar storage capacities. Again, to the best of our knowledge, this is the highest deliverable capacity achieved by any adsorbent after successful pelletisation and shaping.

To design a material for adsorption applications, its volumetric capacity is not the only parameter that needs to be taken into consideration. Looking at the DOE targets, heat management due to the exo/endothermic nature of the adsorption/desorption phenomena, as well as efficient packing of a monolith in a tank, impurity tolerance (e.g. $\mathrm{CO}, \mathrm{H}_{2} \mathrm{O}$ ), recyclability (e.g. 100 cycles) and cost of adsorbent need to be optimized. In the case of monoHKUST-1, the three times higher density compared with that of the powder is expected to improve heat transfer significantly. Moreover, the generic approach of the sol-gel synthesis also allows for doping with materials such as activated carbon with higher thermal conductivity (11). In terms of cost, the primary limiting factors for ${ }_{\text {mono }} \mathrm{HKUST}-1$ production include the starting materials cost, high solvent usage and centrifuge cycling times (5153). Solvent reduction and recovery combined can massively reduce monoHKUST-1 production costs (Fig. S50). Additionally, by employing liquid assisted grinding (LAG), it is possible to significantly reduce mixing times by using prepared nanocrystalline powders to form high-density monoHKUST-1 materials whilst maintaining monolith quality (Fig. S49). Predictably, yield is also a large cost driver, and any cost-effective production will seek to maximize yield. The simplicity of the synthesis of monolithic MOFs combined with their exceptional performance indicates that monolithic MOFs could play an important role in fuel gas storage in the coming decades.

\section{Outlook}

In conclusion, we have investigated computationally the landscape of MOFs for $\mathrm{H}_{2}$ storage and selected HKUST-1 as the optimal structure due to its adsorption capacity and ease of synthesis. 
Following this, we synthesized and analyzed the structure and $\mathrm{H}_{2}$ adsorption properties of the monolithic version, monoHKUST-1. SAXS, NMR spectroscopy and Raman microscopy studies demonstrated that monoHKUST-1 exhibits similar characteristics in terms of composition and connectivity to powdered HKUST-1. However, the small and uniform primary particles result in exceptionally close packing, giving way to high-density final materials when mild drying conditions are applied. The monolithic structure of monoHKUST-1 also gives way to reduced material degradation, a common issue with HKUST-1 powders. The high-density structure forms an oxidised layer on the external surface which reduces the exposure of HKUST-1 particles within the monolith to moisture, maintaining exceptional performance after prolonged periods of exposure to the atmosphere. The exceptional high-density structure of monoHKUST-1 gives way to record-breaking $\mathrm{H}_{2}$ storage performance. The unique synthesis mechanism for monoHKUST-1 enables the formation of materials that maintain porosity after shaping and display benchmark volumetric BET areas which in turn gives way to exceptional $\mathrm{H}_{2}$ sorption performance. The monoHKUST-1 materials were found to be capable of achieving $\mathrm{H}_{2}$ working capacities at 25 bar under cryogenic conditions only possible by compressing $\mathrm{H}_{2}$ to 700 bar at room temperature. This reduction in operating pressures has the potential to significantly reduce the systemwide engineering requirements and cost whilst simultaneously improving the overall safety of onboard $\mathrm{H}_{2}$ storage for vehicular transport. While further development is required to identify more stable materials with high working capacities, this work represents a significant step forward in the shaping and densification of MOFs for $\mathrm{H}_{2}$ storage applications.

\section{References}

1. H. Economy, Looking at the hydrogen economy. Nature. 243, 184-185 (1973).

2. G. Marbán, T. Valdés-Solís, Towards the hydrogen economy? Int. J. Hydrogen Energy. 32, 1625-1637 (2007).

3. J. O. M. Bockris, A hydrogen economy. Science (80-. ). 176, 1323 (1972).

4. U.S Deparment of Energy, DOE Technical Targets for Onboard Hydrogen Storage for Light-Duty Vehicles | Department of Energy. Energy.gov (2017), pp. 1-23.

5. L. Zubizarreta, A. Arenillas, J. J. Pis, Carbon materials for $\mathrm{H}_{2}$ storage. Int. J. Hydrogen Energy. 34, 4575-4581 (2009).

6. K. V. Kumar, K. Preuss, M. M. Titirici, F. Rodríguez-Reinoso, Nanoporous Materials for the Onboard Storage of Natural Gas. Chem. Rev. 117, 1796-1825 (2017).

7. H. Nazir, N. Muthuswamy, C. Louis, S. Jose, J. Prakash, M. E. Buan, C. Flox, S. Chavan, X. Shi, P. Kauranen, T. Kallio, G. Maia, K. Tammeveski, N. Lymperopoulos, E. Carcadea, E. Veziroglu, A. Iranzo, A. M. Kannan, Is the $\mathrm{H} 2$ economy realizable in the foreseeable future? Part II: $\mathrm{H}_{2}$ storage, transportation, and distribution. Int. J. Hydrogen Energy. 45, 20693-20708 (2020).

8. P. Z. Moghadam, A. Li, X. W. Liu, R. Bueno-Perez, S. D. Wang, S. B. Wiggin, P. A. Wood, D. FairenJimenez, Targeted classification of metal-organic frameworks in the Cambridge structural database (CSD). Chem. Sci. 11, 8373-8387 (2020).

9. L. Sarkisov, R. Bueno-Perez, M. Sutharson, D. Fairen-Jimenez, Materials Informatics with PoreBlazer 
v4.0 and the CSD MOF Database. Chem. Mater. 32, 9849-9867 (2020).

10. M. T. Kapelewski, T. Runčevski, J. D. Tarver, H. Z. H. Jiang, K. E. Hurst, P. A. Parilla, A. Ayala, T. Gennett, S. A. Fitzgerald, C. M. Brown, J. R. Long, Record High Hydrogen Storage Capacity in the Metal-Organic Framework $\mathrm{Ni}_{2}(\mathrm{~m}-\mathrm{dobdc})$ at Near-Ambient Temperatures. Chem. Mater. 30, 81798189 (2018).

11. J. Purewal, D. Liu, A. Sudik, M. Veenstra, J. Yang, S. Maurer, U. Müller, D. J. Siegel, Improved hydrogen storage and thermal conductivity in high-density MOF-5 composites. J. Phys. Chem. C. 116, 20199-20212 (2012).

12. J. Purewal, M. Veenstra, D. Tamburello, A. Ahmed, A. J. Matzger, A. G. Wong-Foy, S. Seth, Y. Liu, D. J. Siegel, Estimation of system-level hydrogen storage for metal-organic frameworks with high volumetric storage density. Int. J. Hydrogen Energy. 44, 15135-15145 (2019).

13. J. J. Purewal, D. Liu, J. Yang, A. Sudik, D. J. Siegel, S. Maurer, U. Müller, Increased volumetric hydrogen uptake of MOF-5 by powder densification. Int. J. Hydrogen Energy. 37, 2723-2727 (2012).

14. P. Z. Moghadam, S. M. J. Rogge, A. Li, C. M. Chow, J. Wieme, N. Moharrami, M. Aragones-Anglada, G. Conduit, D. A. Gomez-Gualdron, V. Van Speybroeck, D. Fairen-Jimenez, Structure-Mechanical Stability Relations of Metal-Organic Frameworks via Machine Learning. Matter. 1, 219-234 (2019).

15. B. M. Connolly, D. G. Madden, A. E. H. Wheatley, D. Fairen-Jimenez, Shaping the Future of Fuel: Monolithic Metal-Organic Frameworks for High-Density Gas Storage. J. Am. Chem. Soc. 142, 85418549 (2020).

16. Y. Peng, V. Krungleviciute, I. Eryazici, J. T. Hupp, O. K. Farha, T. Yildirim, Methane storage in metalorganic frameworks: Current records, surprise findings, and challenges. J. Am. Chem. Soc. 135, 1188711894 (2013).

17. T. Tian, Z. Zeng, D. Vulpe, M. E. Casco, G. Divitini, P. A. Midgley, J. Silvestre-Albero, J. C. Tan, P. Z. Moghadam, D. Fairen-Jimenez, A sol-gel monolithic metal-organic framework with enhanced methane uptake. Nat. Mater. 17, 174-179 (2018).

18. K. Suresh, D. Aulakh, J. Purewal, D. J. Siegel, M. Veenstra, A. J. Matzger, Optimizing Hydrogen Storage in MOFs through Engineering of Crystal Morphology and Control of Crystal Size. J. Am. Chem. Soc. 143, 10727-10734 (2021).

19. J. P. Mehta, T. Tian, Z. Zeng, G. Divitini, B. M. Connolly, P. A. Midgley, J. C. Tan, D. Fairen-Jimenez, A. E. H. Wheatley, Sol-Gel Synthesis of Robust Metal-Organic Frameworks for Nanoparticle Encapsulation. Adv. Funct. Mater. 28, 1705588 (2018).

20. B. M. Connolly, M. Aragones-Anglada, J. Gandara-Loe, N. A. Danaf, D. C. Lamb, J. P. Mehta, D. Vulpe, S. Wuttke, J. Silvestre-Albero, P. Z. Moghadam, A. E. H. Wheatley, D. Fairen-Jimenez, Tuning porosity in macroscopic monolithic metal-organic frameworks for exceptional natural gas storage. Nat. Commun. 10, 1-11 (2019).

21. T. Tian, J. Velazquez-Garcia, T. D. Bennett, D. Fairen-Jimenez, Mechanically and chemically robust ZIF-8 monoliths with high volumetric adsorption capacity. J. Mater. Chem. A. 3, 2999-3005 (2015).

22. P. Z. Moghadam, A. Li, S. B. Wiggin, A. Tao, A. G. P. Maloney, P. A. Wood, S. C. Ward, D. FairenJimenez, Development of a Cambridge Structural Database Subset: A Collection of Metal-Organic Frameworks for Past, Present, and Future. Chem. Mater. 29, 2618-2625 (2017).

23. A. Ahmed, S. Seth, J. Purewal, A. G. Wong-Foy, M. Veenstra, A. J. Matzger, D. J. Siegel, Exceptional hydrogen storage achieved by screening nearly half a million metal-organic frameworks. Nat. Commun. 10 (2019), doi:10.1038/s41467-019-09365-w.

24. Z. Chen, P. Li, R. Anderson, X. Wang, X. Zhang, L. Robison, L. R. Redfern, S. Moribe, T. Islamoglu, D. A. Gómez-Gualdrón, T. Yildirim, J. F. Stoddart, O. K. Farha, Balancing volumetric and gravimetric uptake in highly porous materials for clean energy. Science (80-. ). 368, 297-303 (2020).

25. P. García-Holley, B. Schweitzer, T. Islamoglu, Y. Liu, L. Lin, S. Rodriguez, M. H. Weston, J. T. Hupp, D. A. Gómez-Gualdrón, T. Yildirim, O. K. Farha, Benchmark Study of Hydrogen Storage in MetalOrganic Frameworks under Temperature and Pressure Swing Conditions. ACS Energy Lett. 3, 748-754 (2018). 
26. B. R. Barnett, H. A. Evans, G. M. Su, H. Z. H. Jiang, R. Chakraborty, D. Banyeretse, T. J. Hartman, M. B. Martinez, B. A. Trump, J. D. Tarver, M. N. Dods, L. M. Funke, J. Börgel, J. A. Reimer, W. S. Drisdell, K. E. Hurst, T. Gennett, S. A. FitzGerald, C. M. Brown, M. Head-Gordon, J. R. Long, Observation of an Intermediate to $\mathrm{H}_{2}$ Binding in a Metal-Organic Framework. J. Am. Chem. Soc. 143, 14884-14894 (2021).

27. D. Fairen-Jimenez, Y. J. Colón, O. K. Farha, Y. S. Bae, J. T. Hupp, R. Q. Snurr, Understanding excess uptake maxima for hydrogen adsorption isotherms in frameworks with rht topology. Chem. Commun. 48, 10496-10498 (2012).

28. A. Carné-Sánchez, I. Imaz, M. Cano-Sarabia, D. Maspoch, A spray-drying strategy for synthesis of nanoscale metal-organic frameworks and their assembly into hollow superstructures. Nat. Chem. 5, 203-211 (2013).

29. S. L. James, C. J. Adams, C. Bolm, D. Braga, P. Collier, T. Frišcic, F. Grepioni, K. D. M. Harris, G. Hyett, W. Jones, A. Krebs, J. Mack, L. Maini, A. G. Orpen, I. P. Parkin, W. C. Shearouse, J. W. Steed, D. C. Waddell, Playing with organic radicals as building blocks for functional molecular materials. Chem. Soc. Rev. 41, 413-447 (2012).

30. J. et al. Osterrieth, How reproducible are surface areas calculated from the BET equation? ChemRxiv (2021). doi:10.26434/chemrxiv.14291644.v2.

31. M. D. Allendorf, Z. Hulvey, T. Gennett, A. Ahmed, T. Autrey, J. Camp, E. Seon Cho, H. Furukawa, M. Haranczyk, M. Head-Gordon, S. Jeong, A. Karkamkar, D. J. Liu, J. R. Long, K. R. Meihaus, I. H. Nayyar, R. Nazarov, D. J. Siegel, V. Stavila, J. J. Urban, S. P. Veccham, B. C. Wood, An assessment of strategies for the development of solid-state adsorbents for vehicular hydrogen storage. Energy Environ. Sci. 11, 2784-2812 (2018).

32. D. M. Dawson, L. E. Jamieson, M. I. H. Mohideen, A. C. McKinlay, I. A. Smellie, R. Cadou, N. S. Keddie, R. E. Morris, S. E. Ashbrook, High-resolution solid-state ${ }^{13} \mathrm{C}$ NMR spectroscopy of the paramagnetic metal-organic frameworks, STAM-1 and HKUST-1. Phys. Chem. Chem. Phys. 15, 919 929 (2013).

33. C. Prestipino, L. Regli, J. G. Vitillo, F. Bonino, A. Damin, C. Lamberti, A. Zecchina, P. L. Solari, K. O. Kongshaug, S. Bordiga, Local structure of framework $\mathrm{Cu}(\mathrm{II})$ in HKUST-1 metallorganic framework: Spectroscopic characterization upon activation and interaction with adsorbates. Chem. Mater. 18, 1337-1346 (2006).

34. D. O’Nolan, G. Huang, G. E. Kamm, A. Grenier, C. H. Liu, P. K. Todd, A. Wustrow, G. T. Tran, D. Montiel, J. R. Neilson, S. J. L. Billinge, P. J. Chupas, K. S. Thornton, K. W. Chapman, A thermalgradient approach to variable-temperature measurements resolved in space. J. Appl. Crystallogr. 53, 662-670 (2020).

35. A. Terracina, L. N. McHugh, M. Todaro, S. Agnello, P. S. Wheatley, F. M. Gelardi, R. E. Morris, G. Buscarino, Multitechnique Analysis of the Hydration in Three Different Copper Paddle-Wheel MetalOrganic Frameworks. J. Phys. Chem. C. 123, 28219-28232 (2019).

36. L. N. McHugh, M. J. McPherson, L. J. McCormick, S. A. Morris, P. S. Wheatley, S. J. Teat, D. McKay, D. M. Dawson, C. E. F. Sansome, S. E. Ashbrook, C. A. Stone, M. W. Smith, R. E. Morris, Hydrolytic stability in hemilabile metal-organic frameworks. Nat. Chem. 10, 1096-1102 (2018).

37. E. W. Lemmon, M. O. McLinden, D. G. Friend, Thermophysical Properties of Fluid Systems. NIST Chemistry WebBook, NIST Standard Reference Database Number 69, National Institute of Standards and Technology, Gaithersburg MD, 20899 (2005), (available at http://webbook.nist.gov).

38. P. A. Parilla, K. Gross, K. Hurst, T. Gennett, Recommended volumetric capacity definitions and protocols for accurate, standardized and unambiguous metrics for hydrogen storage materials. Appl. Phys. A Mater. Sci. Process. 122, 1-18 (2016).

39. K. E. Hurst, P. A. Parilla, K. J. O’Neill, T. Gennett, An international multi-laboratory investigation of carbon-based hydrogen sorbent materials. Appl. Phys. A Mater. Sci. Process. 122, 1-9 (2016).

40. K. E. Hurst, T. Gennett, J. Adams, M. D. Allendorf, R. Balderas-Xicohténcatl, M. Bielewski, B. Edwards, L. Espinal, B. Fultz, M. Hirscher, M. S. L. Hudson, Z. Hulvey, M. Latroche, D. J. Liu, M. 
Kapelewski, E. Napolitano, Z. T. Perry, J. Purewal, V. Stavila, M. Veenstra, J. L. White, Y. Yuan, H. C. Zhou, C. Zlotea, P. Parilla, An International Laboratory Comparison Study of Volumetric and Gravimetric Hydrogen Adsorption Measurements. ChemPhysChem. 20, 1997-2009 (2019).

41. O. Ardelean, G. Blanita, G. Borodi, M. D. Lazar, I. Misan, I. Coldea, D. Lupu, Volumetric hydrogen adsorption capacity of densified MIL-101 monoliths. Int. J. Hydrogen Energy. 38, 7046-7055 (2013).

42. R. Zacharia, D. Cossement, L. Lafi, R. Chahine, Volumetric hydrogen sorption capacity of monoliths prepared by mechanical densification of MOF-177. J. Mater. Chem. 20, 2145-2151 (2010).

43. A. Dailly, E. Poirier, Evaluation of an industrial pilot scale densified MOF-177 adsorbent as an onboard hydrogen storage medium. Energy Environ. Sci. 4, 3527-3534 (2011).

44. G. Blanita, I. Coldea, I. Misan, D. Lupu, Hydrogen cryo-adsorption by hexagonal prism monoliths of MIL-101. Int. J. Hydrogen Energy. 39, 17040-17046 (2014).

45. O. K. Farha, A. Ö. Yazaydin, I. Eryazici, C. D. Malliakas, B. G. Hauser, M. G. Kanatzidis, S. T. Nguyen, R. Q. Snurr, J. T. Hupp, De novo synthesis of a metal-organic framework material featuring ultrahigh surface area and gas storage capacities. Nat. Chem. 2, 944-948 (2010).

46. D. A. Gómez-Gualdrón, T. C. Wang, P. García-Holley, R. M. Sawelewa, E. Argueta, R. Q. Snurr, J. T. Hupp, T. Yildirim, O. K. Farha, Understanding volumetric and gravimetric hydrogen adsorption tradeoff in metal-organic frameworks. ACS Appl. Mater. Interfaces. 9, 33419-33428 (2017).

47. M. Tian, S. Rochat, K. Polak-Kraśna, L. T. Holyfield, A. D. Burrows, C. R. Bowen, T. J. Mays, Nanoporous polymer-based composites for enhanced hydrogen storage. Adsorption. 25, 889-901 (2019).

48. J. A. Ritter, S. J. Bhadra, A. D. Ebner, On the use of the dual-process langmuir model for correlating unary equilibria and predicting mixed-gas adsorption equilibria. Langmuir. 27, 4700-4712 (2011).

49. D. E. Jaramillo, H. Z. H. Jiang, H. A. Evans, R. Chakraborty, H. Furukawa, C. M. Brown, M. HeadGordon, J. R. Long, Ambient-Temperature Hydrogen Storage via Vanadium(II)-Dihydrogen Complexation in a Metal-Organic Framework. J. Am. Chem. Soc. 143, 6248-6256 (2021).

50. S. Suepaul, K. A. Forrest, T. Pham, B. Space, Investigating the Effects of Linker Extension on $\mathrm{H}_{2}$ Sorption in the rht-Metal-Organic Framework NU-111 by Molecular Simulations. Cryst. Growth Des. 18, 7599-7610 (2018).

51. A. Anastasopoulou, H. Furukawa, B. R. Barnett, H. Z. H. Jiang, J. R. Long, H. M. Breunig, Technoeconomic analysis of metal-organic frameworks for bulk hydrogen transportation. Energy Environ. Sci. 14, 1083-1094 (2021).

52. D. DeSantis, J. A. Mason, B. D. James, C. Houchins, J. R. Long, M. Veenstra, Techno-economic Analysis of Metal-Organic Frameworks for Hydrogen and Natural Gas Storage. Energy and Fuels. 31, 2024-2032 (2017).

53. M. Gaab, N. Trukhan, S. Maurer, R. Gummaraju, U. Müller, The progression of Al-based metal-organic frameworks - From academic research to industrial production and applications. Microporous Mesoporous Mater. 157, 131-136 (2012).

\section{Author Contributions}

D.M. and D.F-J. designed the experiments. D.O.N. performed SAXS fittings, total scattering and PDF studies under the supervision of K.W.C. R.B. and C.C. performed monolith synthesis and physical characterisation. S-Y.Z., J.P. and N.P.M.C. collected SAXS data. D.M. performed low-pressure gas adsorption isotherms. G.A.R. and N.R.C. performed and analysed Raman microscopy studies. A.C.F. performed NMR studies. N.R. performed the high-throughput molecular simulations and principal component analysis; contributed to the writing of the high-throughput screening and PCA sections. 
T.G., P.P., S.S. and K.E.H. performed NREL high-pressure $\mathrm{H}_{2}$ adsorption studies. C.C.C. and J.S.A. performed $\mathrm{Hg}$ porosimetry and University of Alicante high-pressure $\mathrm{H}_{2}$ adsorption studies. D.M. and A.A.S. performed University of Cambridge high pressure experiments. M.D.A. and V.S. provided the powder sample for NREL $\mathrm{H}_{2}$ adsorption experiments. D.M. performed all gas adsorption analyses. D.O.S. and N.P.R. performed calculations on scale-up cost and feasibility. D.M., D.O.N. and D.F-J. co-wrote the paper. All authors discussed the results and commented on the manuscript.

\section{Acknowledgments}

D.F.-J. thanks the European Research Council (ERC) under the European Union's Horizon 2020 research and innovation programme (NanoMOFdeli), ERC-2016-COG 726380 and Innovate UK (104384) and EPSRC IAA (IAA/RG85685). J.S.A. would like to acknowledge the financial support from MINECO (PID2019-108453GB-C21 and PCI2020-111968). N.R.C. thanks the Engineering and Physical Sciences Research Council, United Kingdom (EP/S002995/1) for support. This work was also supported by a UKRI Future Leaders Fellowship to A.C.F. (MR/T043024/1). M.D.A. and V.S. gratefully acknowledge research support from the U.S. Department of Energy, Office of Energy Efficiency and Renewable Energy, Fuel Cell Technologies Office through the Hydrogen Storage Materials Advanced Research Consortium (HyMARC). Sandia National Laboratories is a multimission laboratory managed and operated by the National Technology \& Engineering Solutions of Sandia, LLC, a wholly-owned subsidiary of Honeywell International Inc., for the U.S. Department of Energy's National Nuclear Security Administration under contract DE-NA0003525. The authors acknowledge SOLEIL for provision of synchrotron radiation facility and the SWING beamline for access to the instrumentation (Project No. 20200126). N.R. acknowledges the support of the Cambridge International Scholarship and the Trinity Henry Barlow Scholarship (Honorary). We also thank Prof. Omar Farha (Northwestern University) and Prof. Donald Siegel (University of Michigan) for providing .cif files for NU-1500-Al and UMCM-9, respectively.

\section{Conflict of Interest}

D.F.-J. has a financial interest in the start-up company Immaterial Ltd., which is seeking to commercialize metal-organic frameworks.

\section{Supplementary Materials:}

Materials and Methods

Figures S1-S50 
645 Tables S1-S21

646 References (S1-S40) 